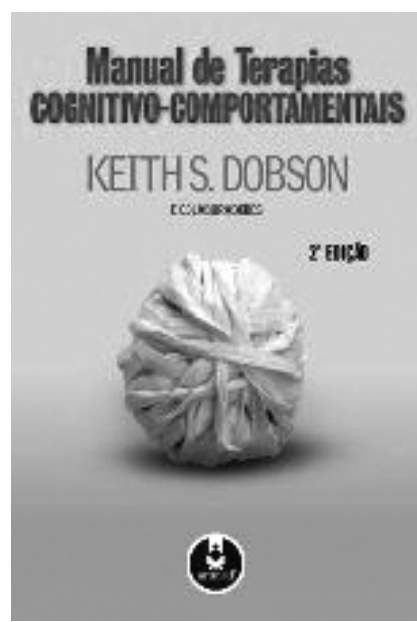

\section{Manual de terapias cognitivo- comportamentais}

Keith S. Dobson (org.)

Porto Alegre, Artmed, 2006, $2^{\mathrm{a}}$ edição

\title{
Patrícia Picon*
}

* Mestre em Epidemiologia, Harvard University, Boston, EUA. Doutora em Psiquiatria, Universidade Federal do Rio Grande do Sul (UFRGS), Porto Alegre, RS. Professora adjunta, Faculdade de Medicina, Pontifícia Universidade Católica (PUCRS), Porto Alegre, RS.

Keith. S. Dobson, $\mathrm{PhD}$, é professor titular e diretor de Psicologia Clínica do Departamento de Psicologia da Universidade de Calgary, em Alberta, Canadá. É pesquisador nas áreas de depressão e psicoterapia cognitivo-comportamental, com mais de uma centena de publicações. No presente livro, por ele organizado, uma versão atualizada da primeira edição de 1988, Dobson reúne os trabalhos de 23 autores da área da psicoterapia cognitivo-comportamental. Os autores são provenientes de renomados centros acadêmicos dos Estados Unidos, Canadá e Inglaterra. Entre eles, podemos destacar Aaron T. Beck e Robert J. DeRubeis, da Universidade da Pensilvânia; Albert Ellis, do Instituto Albert Ellis de Terapia Comportamental Racional-Emocional de Nova York; Larry E. Bleutler, Roslyn Caldwell, Joan Davdson T. Mark Harwood e Jacqueline B. Persons, da Universidade da Califórnia; Windy Dryden, da Universidade de Londres; e Kirk R. Blanstein e Zindel V. Segal, da Universidade de Toronto.

Como pesquisador e clínico no campo das psicoterapias cognitivo-comportamentais, Dobson teve a oportunidade, nas últimas duas décadas, de testemunhar o crescimento da riqueza clínica, assim como dos avanços na avaliação da eficácia de seus modelos de intervenção, como menciona em seu prefácio. O editor salienta a importância das inovações das psicoterapias cognitivo-comportamentais e refere que o livro reflete esse crescimento. O objetivo da obra é o de abordar as terapias cognitivo-comportamentais a partir de uma perspectiva teórica, fugindo do modelo de livro em que os transtornos psiquiátricos servem como organizador para a exposição de tratamentos diferenciados. A idéia é a de explorar o crescimento dos vários modelos cognitivo-comportamentais, fornecendo um arcabouço conceitual atualizado aos leitores interessados.

Dobson considera como psicoterapia cognitivocomportamental aquela intervenção que se baseia no modelo mediacional, ou seja, em que uma mudança cognitiva deva mediar ou levar a uma mudança comportamental. Destaca que algumas psicoterapias têm enfoque mais cognitivista, outras mais comportamentalistas, mas que todas buscam mudanças adaptativas e que a avaliação de resultados segue sendo fundamental. Dobson reconhece a considerável resistência para a implementação de práticas psicoterápicas de base empírica, mas apóia o 
atual movimento de utilização de critérios empíricos para indicação das diferentes psicoterapias cognitivocomportamentais.

A primeira parte do livro trata de questões conceituais e tem cinco capítulos: fundamentos históricos e filosóficos das terapias cognitivocomportamentais; avaliação cognitiva: processos e métodos; a formulação de caso cognitivocomportamental; cognição e ciência clínica: da revolução à evolução; e a integração entre as terapias cognitivo-comportamentais. O capítulo cinco foi escrito por Larry E. Beutler, T. Mark Harwood e Roslyn Caldwell, que discorrem basicamente sobre as diferentes abordagens ecléticas das psicoterapias cognitivo-comportamentais. Os autores descrevem o ecletismo casual como a abordagem mais praticada, porém a menos sistematizada. Referem que o integracionismo teórico é amplamente praticado, mas, por ser muito abstrato, encontra dificuldades para proporcionar orientação clara e prática para a implementação de protocolos de tratamento. O ecletismo sistemático, por outro lado, pode sofrer por ser limitado e muito ateórico. No transcorrer do capítulo, os autores propõem que os fundamentos teóricos e práticos das psicoterapias cognitivas e cognitivo-comportamentais, em particular a terapia cognitiva de Aaron Beck e seus seguidores, proporcionam a estrutura teórica e a plataforma de técnicas necessárias para desenvolver intervenções ecléticas estratégicas e passíveis de mensuração.

A terapia cognitiva foi desenvolvida por Aaron Beck, na Universidade da Pensilvânia, no início da década de 60, como uma psicoterapia breve, estruturada, orientada para o presente, para a depressão, direcionada para a resolução de problemas atuais e para modificar comportamentos disfuncionais. Desde então, Beck e seus seguidores vêm adaptando com sucesso essa terapia para um conjunto surpreendentemente diverso de populações e desordens psiquiátricas, mantendo seus pressupostos teóricos básicos ${ }^{1}$.

No referido capítulo cinco do livro organizado por Dobson, seus autores salientam, ainda, a necessidade de ampliar a especificidade dos procedimentos das psicoterapias cognitivas e cognitivo-comportamentais, através de uma maior integração dos mesmos a dimensões como o nível de limitação, resistências, estilos de enfrentamento e nível de perturbação dos pacientes. Assim, recomendações relacionadas à freqüência e à duração do tratamento, o grau de direcionamento, o foco em sintomas ou pensamentos esquemáticos e a atenção a cognições quentes (carregadas de emoção) poderiam ajudar a aumentar os efeitos da terapia cognitiva.

Na segunda parte do livro, temos seis capítulos que descrevem as terapias de autocontrole, de resolução de problemas, cognitivo-comportamental para crianças, racional-emotiva, cognitiva e variedades de construtivismo em psicoterapia.

Segundo Abreu \& Roso, as concepções cognitivas construtivistas pressupõem que o trabalho da significação encontra-se, primeiramente, subordinado à influência das emoções, e não à dialética da razão. Nessa concepção teórica, o funcionamento da mente não só reflete o mundo exterior, mas também o transpõe, atribuindo significados que, muitas vezes, não são originários do estímulo em si. Assim, a realidade interna será vista como fundamentalmente derivada do modo como cada individuo sente emocionalmente o mundo, e não só como o concebe de maneira racional. No construtivismo, as emoções encontram um papel mais central e precedem a construção racional da percepção do mundo e de si mesmo que o sujeito tem, como preconiza a teoria cognitiva desenvolvida por Aaron Beck, onde as emoções são derivadas dos padrões de pensamento que, pautados nas crenças, direcionam a maneira como as pessoas interpretam as situações a que estão expostas $^{2}$.

Nesta segunda parte do livro organizado por Dobson, os capítulos são escritos ou pelos idealizadores das diferentes abordagens cognitivocomportamentais, como Aaron Beck e Albert Ellis, ou, ainda, por destacados conhecedores de cada uma dessas terapias. Todos os capítulos trazem revisões abrangentes, que incluem, além de aspectos históricos, a descrição de modelos teóricos, principais técnicas e resultados de pesquisas de eficácia, com dados atualizados.

\section{Referências}

1. Beck J. Terapia cognitiva: teoria e prática. Porto Alegre: Artmed; 1997.

2. Abreu CN, Roso M. Psicoterapias cognitiva e construtivista: novas fronteiras da prática clínica. Porto Alegre: Artmed; 2003. 